\title{
Virtual Health Information Infrastructures: A Scalable Regional Model
}

\author{
Ann Séror \\ eResearch Collaboratory, 352 Rue Lavigueur, Quebec City, Canada G1R 1B4 \\ annseroreeresearchcollaboratory.com
}

\begin{abstract}
Integrating research, education and evidence-based medical practice requires complex infrastructures and network linkages among these critical activities. This research examines communities of practice and open source software tools in development of scalable virtual infrastructures for the regional Virtual Health Library of the Latin American and Caribbean Health Sciences System (Bireme) and embedded national cases. Virtual infrastructures refer to an environment characterized by overlapping distribution networks accessible through Internet portals and websites designed to facilitate integrated use of available resources. Case analysis shows engagement of interdisciplinary communities of practice for scalable virtual infrastructure design. This research program considers theory and methods for study of transferability of the Latin American model to large health care systems in other cultures.
\end{abstract}

Keywords: virtual infrastructures, open source systems, communities of practice, Bireme, culture.

Information technologies and telecommunication infrastructures are transforming institutions at the foundation of evidence-based research, education and practice in medicine and the health sciences. Emerging health information networks offer integrated systems to link these complex activities for innovation in health care service delivery. There is growing recognition in scientific communities of the critical importance of networks in social systems in general as well as in health care. [1,2] The OSS community offers substantial resources to build infrastructures at the foundation of health information networks. [3] Recent literature recognizes that access to health information for health care providers, policy makers, researchers, publishers, and systematic reviewers is essential to global development of equitable health care systems as well as achievement of the Millennium Development Goals. [4] In this fast developing field of inquiry, only fragmented research has focused on the design and scaling of collaborative health information systems taking into account the institutional roles of virtual infrastructures.

Studies of the Latin American and Caribbean Health Sciences System (Bireme) suggest the importance of local research and publication as well as regional leadership to integrate medical education and practice. [5-8] Emerging open access publishing systems reveal new dynamics between international and national as well as academic and practitioner communities, while the social medicine tradition of the Latin American region illustrates the power of ideology as a factor shaping integrated 
regional and local health information systems. Virtual infrastructures supporting these systems refer to an environment characterized by overlapping distribution networks, systems brokerage functions, and the adoption of a software perspective emphasizing the devices and channels through which information is processed and distributed. [9] The diversity of such systems means that technology varies, in particular as a function of technological choices based on local and regional ideologies and traditions. The health care system is defined here as a dynamic set of interconnected individuals, institutions, organizations, and projects offering products and services in health care markets. [10] Ruef [11] suggests that inclusion in an ecological field - such as a complex national health care system - should be determined in the context of broad system functions and their linkages. These linkages may be social, functional, geographical, and temporal as well as virtual.

Nonaka has described the complex Japanese concept of "ba" as "a shared space for emerging relationships" that may be physical, virtual or mental in nature reflecting the individual in the collective "all". [12,13] "Ba" poses the foundation for translation of information into knowledge, and the temporal and spatial frame for its use. In this study, "ba" represents the health care system knowledge ecology linking communities of practice and virtual infrastructures contributing to translation of information into knowledge and care delivery. Communities of practice are defined here as groups of people sharing a focus on a common interest or task and interacting regularly to improve their knowledge or performance. [14-17] While research, education and practice in health care may form independent professional communities; researchers, learners and practitioners may also create both social and intellectual capital through mutual and reciprocal engagement. [18]

Effective system integration at the country and regional levels of analysis is particularly evident in the Latin American social medicine model where communities of practice share common ideologies [19] associated with universal health care, public education in medicine and the health sciences, open access publishing of health information and research, and infrastructure creation through open source software development. Some experience suggests that the open source model for software development may be extended to research in the health sciences, pointing to the ideological coherence between infrastructure development and productive activities conducted within such infrastructure. [20-22] Virtual infrastructures, accessible on the Internet offer visible evidence of ecological domains for mapping and analysis of their configurations at micro-, meso- and meta-levels of structure. The research questions considered here are:

- What is the emergent configuration of virtual infrastructures integrating regional and national health information systems and knowledge ecologies?

- What are the roles of human resources and open source communities of practice in these ecological systems?

- What factors determine the transferability of this scalable model to other large system contexts?

The methodology for this qualitative research program is embedded case analysis suggested by Yin. [23] The Latin American and Caribbean Health Sciences System (Bireme) forms the context in which national information systems have developed. 
This choice of case is revelatory of the reciprocal roles of regional and country level leadership in this process. While qualitative methods may not yield generalizable conclusions, they contribute to rich description of regional and national knowledge ecologies and the ideological role of the social medicine model shared among countries of the Latin American region. [24] Data are drawn from published accounts of system development [25] and the websites of the constituent organizations, networks and services to describe the configuration of virtual infrastructures. [26,27] E-mapping software is used to visualize maps of the linkages among resources identified in the knowledge ecology of the regional Virtual Health Library of the Latin American and Caribbean Health Sciences System (Bireme). [28,29] The maps generated using this methodology show how global, regional and national open source resources are shared and integrated by users in the virtual infrastructure. [30,31] Open source ideology and culture are considered in development of a model of transferability of the Bireme system to other large regional systems such as those in China and India.

\section{References}

1. Barabási, A.-L.: Linked: How Everything is Connected to Everything Else and What It Means for Business, Science, and Everyday Life. Basic Books, New York (2003)

2. PloS Medicine (eds) It's the Network, Stupid: Why Everything in Medicine is Connected. PLoS Med. 5, e71 (2008)

3. Reynolds, C., Wyatt, J.: Open Source, Open Standards, and Health Care Information Systems. J. Med. Internet Res. 13, e24 (2011)

4. Godlee, F., Pakenham-Walsh, N., Ncayiyana, D., Cohen, B., Packer, A.: Can We Achieve Health Information for All by 2015? Lancet 364, 295-300 (2004)

5. Meneghini, R., Mugnaini, R., Packer, A.: International versus National Oriented Brazilian Scientific Journals: A Scientometric Analysis Based on SciELO and JCR-ISI Databases. Scientometrics 69, 529-538 (2006)

6. Meneghini, R., Packer, A.: Is There Science Beyond English? EMBO Reports 8, 112-116 (2007)

7. Packer, A.: SciELO as a Model for Scientific Communication in Developing Countries: Origins, Evolution, Current Status, Management and Perspectives of the SciELO Network of Open Access Collections of Ibero-America Journals. CODATA 2007 - Strategies for Open and Permanent Access to Scientific Information in Latin America: Focus on Health and Environment Information for Sustainable Development. Sao Paulo, Brazil, May 8-10 (2007)

8. Packer, A.: The SciELO Model for Electronic Publishing and Measuring of Usage and Impact of Latin American and Caribbean Scientific Journals. In: Second UCSU/UNESCO International Conference on Electronic Publishing in Science, February 20-23 (2001)

9. Séror, A.: A Case Analysis of INFOMED: The Cuban National Health Care Telecommunications Network and Portal. J. Med. Internet Res. 8, e1 (2006)

10. Alliance for Health Policy and Systems Research: Strengthening Health Systems: The Role and Promise of Policy and Systems Research. Global Forum for Health Research, Geneva (2004)

11. Ruef, M.: The Emergence of Organizational Forms: A Community Ecology Approach. Am. J. Sociol. 106, 658-714 (2000) 
12. Nonaka, I.: The Concept of "Ba": Building a Foundation for Knowledge Creation. Calif. Manage. Rev. 40, 40-54 (1998)

13. Nonaka, I.: A Dynamic Theory of Organizational Knowledge Creation. Organ. Sci. 5, 1437 (1994)

14. Wenger, E.: Communities of Practice: Learning as a Social System. Systems Thinker 9, 18 (1998)

15. Wenger, E.: Communities of Practice: Learning, Meaning, and Identity. Cambridge University Press, Cambridge (1998)

16. Edwards, K.: Epistemic Communities, Situated Learning and Open Source Software Development. MIT Working Paper (2001)

17. Haas, P.: Introduction: Epistemic Communities and International Policy Coordination. Int. Organ. 46, 1-35 (1992)

18. McDonald, P.W., Viehbeck, S.: From Evidence-Based Practice Making to Practice-Based Evidence Making: Creating Communities of (Research) and Practice. Health Promot. Pract. 8, 140-144 (2007)

19. Committee for Economic Development (CED): Open Standards, Open Source, and Open Innovation: Harnessing the Benefits of Openness. Washington, D.C. (2008)

20. Anonymous: An Open-source Shot in the Arm? The Economist (June 10, 2004)

21. Maurer, S., Rai, A., Sali, A.: Finding Cures for Tropical Diseases: Is Open Source an Answer? PLoS Med. 1, 180-183 (2004)

22. Mueller, M.: Info-Communism? Ownership and Freedom in the Digital Economy. First Monday 13 (2008)

23. Yin, R.: Case Study Research: Design and Methods. Sage, London (2002)

24. Collier, D., Mahoney, J.: Insights and Pitfalls: Selection Bias in Qualitative Research. World Polit. 49, 56-91 (1996)

25. VHL Guide (2011), http: / / guiabvs2011.bvsalud.org/en/presentation/

26. Vidal Ledo, M.C., Febles Rodríguez, P., Estrada Sentí, C.V.: Mapas Conceptuales. Educación Médica Superior 21 (2007)

27. Rodriguez Pina, R.A., Guerra Avila, E.: Mapas Conceptuales y Geo-referencias en Productos y Servicios de Inteligencia Empresarial. In: ACIMED, vol. 17 (2008)

28. Egbu, C., et al.: Knowledge Mapping and Bringing about Change for the Sustainable Urban Environment. In: Engineering and Physical Sciences Research Council (EPSRC), Glasgow (2006)

29. Ruffini, M.: Using E-Maps to Organize and Navigate Online Content. EDUCAUSE Quarterly 31, 56-61 (2008)

30. Ebener, S., Khan, A., Shademani, R., Compernolle, L., Beltran, M., Lansang, M.A., et al.: Knowledge Mapping as a Technique to Support Knowledge Translation. B. World Health Organ. 84, 636-642 (2006)

31. Lavis, J., Lomas, J., Hamid, M., Sewankambo, N.: Assessing Country-Level Efforts to Link Research to Action. B. World Health Organ. 84, 620-628 (2006) 